\title{
Role of TRAP1 and estrogen receptor alpha in patients with ovarian cancer -A study of the OVCAD consortium
}

\author{
Stefanie Aust ${ }^{1}$, Anna Bachmayr-Heyda ${ }^{1}$, Petra Pateisky ${ }^{1}$, Dan Tong ${ }^{1}$, Silvia Darb-Esfahani ${ }^{2}$, Carsten Denkert ${ }^{2}$, \\ Radoslav Chekerov ${ }^{2}$, Jalid Sehouli ${ }^{2}$, Sven Mahner ${ }^{3}$, Toon Van Gorp ${ }^{4,5}$, Ignace Vergote ${ }^{4}$, Paul Speiser ${ }^{1}$, \\ Reinhard Horvat ${ }^{6}$, Robert Zeillinger ${ }^{1}$ and Dietmar Pils ${ }^{1 *}$
}

\begin{abstract}
Background: The role of the tumor necrosis factor receptor associated protein 1 (TRAP1) - supposed to be involved in protection of cells from apoptosis and oxidative stress - has just started to be investigated in ovarian cancer. TRAP1 has been shown to be estrogen up-regulated in estrogen receptor a (ERa) positive ovarian cancer cells. The clinical impact of TRAP1 is not clear so far and the significance of ERa expression as therapeutic and prognostic marker is still controversial. Therefore, we investigated the importance of TRAP1 together with ERa in regard to clinicopathological parameters, chemotherapy response, and survival.

Methods and results: Expressions of TRAP1 and ERa were evaluated by immunohistochemical staining of tissue microarrays comprised of 208 ovarian cancer samples. TRAP1 was highly expressed in 55\% and ERa was expressed in $52 \%$ of all cases. High TRAP1 expression correlated significantly with ERa $(p<0.001)$ but high TRAP1 expression was also found in $42 \%$ of ERa negative cases. High TRAP1 expression correlated significantly with favorable chemotherapy-response $(\mathrm{HR}=0.48 ; 95 \% \mathrm{Cl} 0.24-0.96, \mathrm{p}=0.037)$ and showed a significant impact on overall survival (OS) $(\mathrm{HR}=0.65 ; 95 \% \mathrm{Cl} 0.43-0.99, \mathrm{p}=0.044)$. ERa expression was a favorable prognostic factor for OS in univariate and multivariate analyses. Interestingly, the combined pattern (ERa positive and/or TRAP1-high) revealed the strongest independent and significant positive influence on OS ( $H R=0.41 ; 95 \% \mathrm{Cl} 0.27-0.64)$.

Conclusion: Immunohistochemical evaluation of TRAP1 together with ERa provides significant prognostic information. TRAP1 alone is significantly associated with chemotherapy response and overall survival, rendering TRAP1 as interesting scientific and therapeutic target.
\end{abstract}

Keywords: TRAP1, Estrogen receptor, Immunohistochemistry, Prognosis, Ovarian cancer

\section{Introduction}

Molecular chaperones of the Hsp90 (90-kDa heat shock protein) family are involved in cancer development and malignant progression. TRAP1/Hsp75 (tumor necrosis factor receptor associated protein 1), a paralogue of the Hsp90 family, has been recently described as a molecular marker and novel therapeutic target in local and metastatic prostate cancer [1]. Increased expression of TRAP1 in multidrug resistant colorectal cancer was

\footnotetext{
* Correspondence: dietmar.pils@univie.ac.at

'Department of Obstetrics and Gynecology Molecular Oncology Group, Medical University of Vienna, Vienna, Austria

Full list of author information is available at the end of the article
}

suggested to favor chemotherapy resistance [2]. In breast cancer cells, HSPs influence tumorigenesis [3] and in ovarian cancer, TRAP1 has recently been questioned as a new potential molecular target [4].

Ovarian cancer is the leading cause of death from gynecologic malignancies in western countries, whereby peritoneal metastasis and chemotherapy resistance as well as relapse after chemotherapy remain scientific and clinical challenges. Trying to understand the mechanisms involved in cancer progression and chemotherapy resistance in epithelial ovarian carcinoma (EOC), the role of heat shock proteins, including TRAP1, has just started to be investigated [4-6].

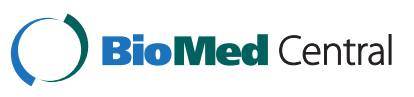


Chemotherapy effectiveness depends to a high amount on the ability of ovarian cancer cells to undergo drug-induced apoptosis [7]. TRAP1, described to be involved in apoptosis evasion, was observed to be significantly up-regulated in Cisplatin resistant ovarian tumor cell lines [8]. Microarray analysis of expression changes in human ER $\alpha$-positive ovarian cancer cell lines upon 17ß-estradiol stimulation, identified TRAP1 to be estrogen up-regulated and to be involved in growth regulation of EOC [9]. In certain EOCs, high levels of $E R \alpha$ are frequently expressed at time of diagnosis and expression levels of ER $\alpha$ dependent up-regulated proteins such as TRAP1 were discussed to predict endocrine responsiveness [10].

However, the importance of ER $\alpha$ expression as therapeutic and prognostic marker in EOC is still controversial [11]. Prognostic significance of ER $\alpha$ expression was recently described as favorable, revealing a significantly longer overall survival [12-14]. However, in other studies this was not observed $[15,16]$. In young women, the expression of ER alone was not associated with favorable survival but the combination of $\mathrm{ER}+/ \mathrm{PR}+$ revealed a superior overall survival [17]. Additionally, superior prognosis was described in ER-/PR + invasive ovarian cancer [18] when compared to all other combinations. Thus, TRAP1 might become of relevance when predictors of endocrine therapy response in EOC will be further elucidated.

Up to now, only a limited number of studies have focused on this Hsp90 related molecule and most of the results were obtained from cell line models or mouse models $[19,20]$. TRAP1's levels are consistently elevated in several human malignancies (i.e. colon, prostate, and nasopharyngeal carcinomas), while present at very low levels, and sometimes undetectable in the corresponding normal tissues. In EOC, a number of studies have investigated the association of differences in gene expression at time of primary surgery and therapy-response [21,22]. It has been demonstrated that estrogen-regulated gene expression can predict response to endocrine therapy with the aromatase inhibitor Letrozole in patients with ovarian cancer. The expression of estrogen-regulated genes such as TRAP1, TFF1, TFF3, TOP2A and UBE2C was significantly different between CA125 progressors and non-progressors in a sample of 42 patients after treatment with Letrozole, whereby TRAP1 was significantly increased in Letrozole-responsive patients [10].

The aim of our study was to further clarify the role of TRAP1 in a large and homogenous sample of human EOC in regard to clinicopathological parameters, therapy response, and patient outcome. We examined the pattern of TRAP1 expression in prospectively collected ovarian tumor tissue from 208 non-FIGO I patients collected in the course of the EU-project OVCAD (Ovarian
Cancer: Diagnosis of a silent killer, no. 018698). To better understand the function of TRAP1 and to provide further insight into the relationship between ER $\alpha$ expression and tumor behavior as well as patients' outcome, expression levels of ER $\alpha$ were analyzed as well and correlated with clinicopathological parameters.

\section{Materials and methods \\ Patients cohort}

Within the context of the FP6 EU-project OVCAD (http://www.ovcad.org), samples from primary EOC were prospectively collected at the University clinics of Berlin, Hamburg, Innsbruck, Leuven, and Vienna (OVCAD-consortium). Samples were collected according to standard operation procedures established in OVCAD. Clinical and histopathological data as well as follow-up data were collected by experienced clinicians. Patients presenting with benign ovarian diseases, FIGO I stage EOC or secondary malignant diseases were excluded. $85 \%$ of Patients were treated according to standards of the institutions involved with upfront surgery and adjuvant platinum-based chemotherapy. A total of 31 patients $(14.9 \%)$ were treated with neoadjuvant chemotherapy (platinum-based) followed by an intervention-debulking and further adjuvant chemotherapy. Only patients with debulking surgery and platinum-based chemotherapy were included to the OVCAD patient cohort. The study protocol was approved by the Ethics Committees of the participating OVCAD partners. All patients gave pre-operative written informed consent before enrollment in the study. Overall survival (OS) was defined as the time interval between diagnosis and cancer correlated death and progression free survival (PFS) as the time between diagnosis and disease progression. Overall observation time was the time interval between diagnosis and last contact, defined as death or last follow-up. Therapy response to chemotherapy was defined according to the WHO criteria; i.e. progression of disease after first-line chemotherapy was defined by an increase in the nadir serum CA-125 level of at least two according to the GCIG criteria or by radiological confirmation. Patients were classified as non-responder if progression was diagnosed during treatment or recurrence within six months after end of first-line chemotherapy. Patients without recurrence, cancer progression or death were censored at the time of last follow-up. Experienced gynecological oncologists and pathologists performed the clinical and histopathological evaluation and the evaluation of response to first-line treatment.

\section{Immunostaining}

Five tissue microarrays (TMAs) comprised of two tissue sections of 208 patients per patient were analyzed. 
Samples were collected between 2006 and 2008. Mitochondrial staining of monoclonal rabbit anti-TRAP1 antibody (1:1,000; Cat-Id/Clone-ID 3609-1/EPR5381, Epitomics, USA) was verified by a colocalization analysis employing double-immunofluorescence staining with mouse anti-COX5 antibody as mitochondrial marker (1:250; Invitrogen). The fluorescence labeled secondary antibodies, goat anti-rabbit (1:5,000; Invitrogen, AlexaFluor $^{\circledR} 488$ fragment of goat anti-rabbit IgG $\left.(\mathrm{H}+\mathrm{L})\right)$ and goat anti-mouse (1:5,000; Invitrogen, AlexaFluor ${ }^{\circledR} 568$ goat anti-mouse IgG1) were used besides DAPI for nuclear counterstaining. For the TMA, two replicate $1 \mathrm{~mm}$-diameter cores were obtained. Three $\mu \mathrm{m}$ sections were deparaffinized, rehydrated, and quenched for endogenous peroxidase by incubating with $3 \% \mathrm{H}_{2} \mathrm{O}_{2}$. For TRAP1 staining (1:3,000; Epitomics) epitope heat retrieval was performed by microwaving the slides in EDTA (0.01 M, pH 8.0). Samples were blocked with blocking solution (Ultra V Block; TA-015HP) for $7 \mathrm{~min}$ and then the primary TRAP1 antibody was added for one hour at room temperature. As a positive control, kidney tissue sections were used and for negative control, a rabbit immunoglobulin control. For enhancement, slides were incubated with primary antibody enhancer (Primary Antibody Enhancer; TL-015-PB) for $10 \mathrm{~min}$ followed by a HRP Polymer (HRP Polymer; TL-015-PH) for $15 \mathrm{~min}$. Finally, slides were incubated with diaminobenzidin as a chromogen, counterstained with hematoxylin, dehydrated and mounted.

TRAP1 expression levels were determined using a scoring system based on the intensity of staining (0-3) compared to the negative control (0). Samples were examined by three independent observers, including a gynecological pathologist, whereby rescoring was conducted in samples with inconsistent scoring, leading to the following groups: negative (0); weak (1); moderate (2); and strong (3) staining. For statistical analysis classification into TRAP1-high and TRAP1-low was performed according to strong versus negative to moderate expression levels, respectively.

Staining for ER $\alpha$ (1:50; ER $\alpha$, clone 1D5, mouse IgG1, Dako, Denmark) was performed using standard immunohistochemical techniques. The intensity patterns and nuclear positivity of ER $\alpha$ staining were analyzed by two independent co-workers, including a gynecological pathologist, applying a semi-quantitative scale of ImmunoReactive Score (IRS) including intensity of color reaction and percentage of positive cells. The intensity of reaction was scored as negative (intensity $0,<10 \%$ positive cells) or positive (intensity $1-3,>10 \%$ positive cells).

\section{Statistical analysis}

Statistical analyses were performed using SPSS software version 19 (IBM Corporation, Armonk, New York,
USA). Correlations between TRAP1-expression, ER $\alpha$-expression, and clinicopathological parameters were assessed by T-tests, Chi-square tests, and Fisher's exact tests as appropriate. Results were adjusted for multiple testing by the Bonferroni-Holm method [23]. To analyze ER $\alpha$ together with TRAP1 expression, patients were classified into four groups: i) ER $\alpha$-/TRAP1-low; ii) ER $\alpha-/$

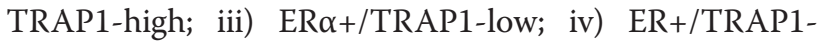
high; For survival analyses and impact on chemotherapy response, the following combination pattern was included in the calculations: i) a group comprised of ER $\alpha$-/TRAP1-low versus ii) a group comprised of the other three combinations. Impact on progression free survival and overall survival was determined by univariate and multiple Cox proportional-Hazards model analyses. Impact on chemotherapy response was determined by uni- and multivariate logistic regression models. In addition, the univariate impact was illustrated by Kaplan-Meier estimates whereby differences in survival were analyzed by the Log-rank test.

Table 1 Characteristics of the study population

\begin{tabular}{|c|c|c|c|c|}
\hline \multicolumn{5}{|c|}{ Study population divided into TRAP1-low and TRAP1-high } \\
\hline $\mathrm{N}=\mathbf{2 0 8}$ & TRAP1-low & TRAP1-high & & \\
\hline Characteristics & $\begin{array}{c}n=93 \\
(\%)\end{array}$ & $\begin{array}{c}n=115 \\
(\%)\end{array}$ & $\mathbf{p}$ & Adjusted $\mathrm{p}$ \\
\hline \multicolumn{5}{|l|}{ Age } \\
\hline$\leq 55(n=98)$ & $49(23.6)$ & 49 (23.6) & & \\
\hline$>55(n=110)$ & $44(21.2)$ & $66(31.7)$ & 0.148 & \\
\hline \multicolumn{5}{|l|}{ Histology } \\
\hline Serous $(n=183)$ & $76(36.5)$ & $107(51.4)$ & & \\
\hline Non-serous ${ }^{1}(n=25)$ & $17(8.2)$ & $8(3.8)$ & 0.013 & 0.078 \\
\hline \multicolumn{5}{|l|}{ FIGO } \\
\hline$\|(n=9)$ & $5(2.4)$ & $4(1.9)$ & & \\
\hline III $(n=164)$ & 70 (33.6) & $94(45.2)$ & $0.526^{2}$ & \\
\hline IV $(n=35)$ & $18(8.7)$ & $17(8.2)$ & & \\
\hline \multicolumn{5}{|l|}{ Grade (1 missing) } \\
\hline Grade $1 \& 2(n=55)$ & $19(9.2)$ & $36(17.4)$ & & \\
\hline Grade $3(n=152)$ & 73 (35.3) & 79 (38.2) & 0.087 & \\
\hline \multicolumn{5}{|l|}{ Residual tumor } \\
\hline no $(n=146)$ & $64(30.8)$ & $82(39.4)$ & & \\
\hline$>0 \mathrm{~cm}(\mathrm{n}=62)$ & 29 (13.9) & $33(15.9)$ & 0.697 & \\
\hline \multicolumn{5}{|c|}{ Peritoneal Carcinomatosis } \\
\hline no $(n=64)$ & $28(13.5)$ & $36(17.3)$ & & \\
\hline yes $(n=144)$ & 65 (31.5) & 79 (38.0) & 0.852 & \\
\hline
\end{tabular}

${ }^{1}$ Endometrioid $(n=9)$, mixed epithelial $(n=9)$, mucinous $(n=1)$, undifferentiated $(n=4)$, and clear-cell carcinoma $(n=2)$. ${ }^{2}$ Fisher's Exact test. 


\section{Results}

\section{Study population}

Tumor tissues of 208 EOC patients were used. Median age at time of cytoreductive surgery was 56 years (range 18-85 years). All 9 (4\%) patients with FIGO II EOC received optimal cytoreductive surgery as well as 137 (66\%) of the 199 patients diagnosed with FIGO III and IV. Within the observation period 96 patients died and the median follow up was 51 months. The clinicopathological characteristics of the 208 EOCs classified as TRAP1-high or TRAP1-low are shown in Table 1. No significant differences were found for the clinicopathological parameters between the two groups (adjusted p-values).

\section{Immunohistochemical evaluation}

Initially, expression of the molecular chaperone TRAP1 in human ovarian cancer was determined by immunohistochemistry. 115 patients were classified as TRAP1high (55.3\%) and 93 patients as TRAP1- low (44.\%), comprising moderate, low, and negative expression in 57 (27.4\%), 25 (12.0\%), and 11 (5.3\%) samples, respectively. To proof the mitochondrial expression of the used antibody, a colocalization experiment was conducted, using the mitochondrial marker COX5 together with TRAP1. In Figure 1, an example of this double-staining is given, showing the mitochondrial localization of TRAP1 in an EOC tissue. On the TMA, tumor tissue showed a distinct specific intracytoplasmatic granular staining, reflecting the expected mitochondrial localization. To confirm the antibody specificity, a Western blot and staining of paraffin embedded agarose cell blocks of four cell lines (two with high, one with weak, and one with nearly no TRAP1 expression) have been conducted. The Western blot showed a perfect specificity (no additional bands besides the correct band at $\left.M_{r} \sim 75,000\right)$ of the TRAP1 antibody. A near perfect correlation of the Western band intensities to the staining intensities of the corresponding stainings of the agarose cell blocks was observed (supplementary data in additional file 1). Samples of studied ovarian cancer tissues with variable staining intensities are presented in Figure 2A. Tumorsurrounding stromal tissue showed no TRAP1 expression (Figure 2A).

The results of ER $\alpha$ immunohistochemistry analysis revealed 99 (48\%) ER $\alpha$ negative and 109 (52\%) ER $\alpha$ positive cases. Representative pictures of ER $\alpha$ staining are provided in Figure 2B. Table 2 describes the characteristics of ER $\alpha$ positive and negative patients. There was a significant correlation between ER $\alpha$ expression and the histological classification: tumors of non-serous
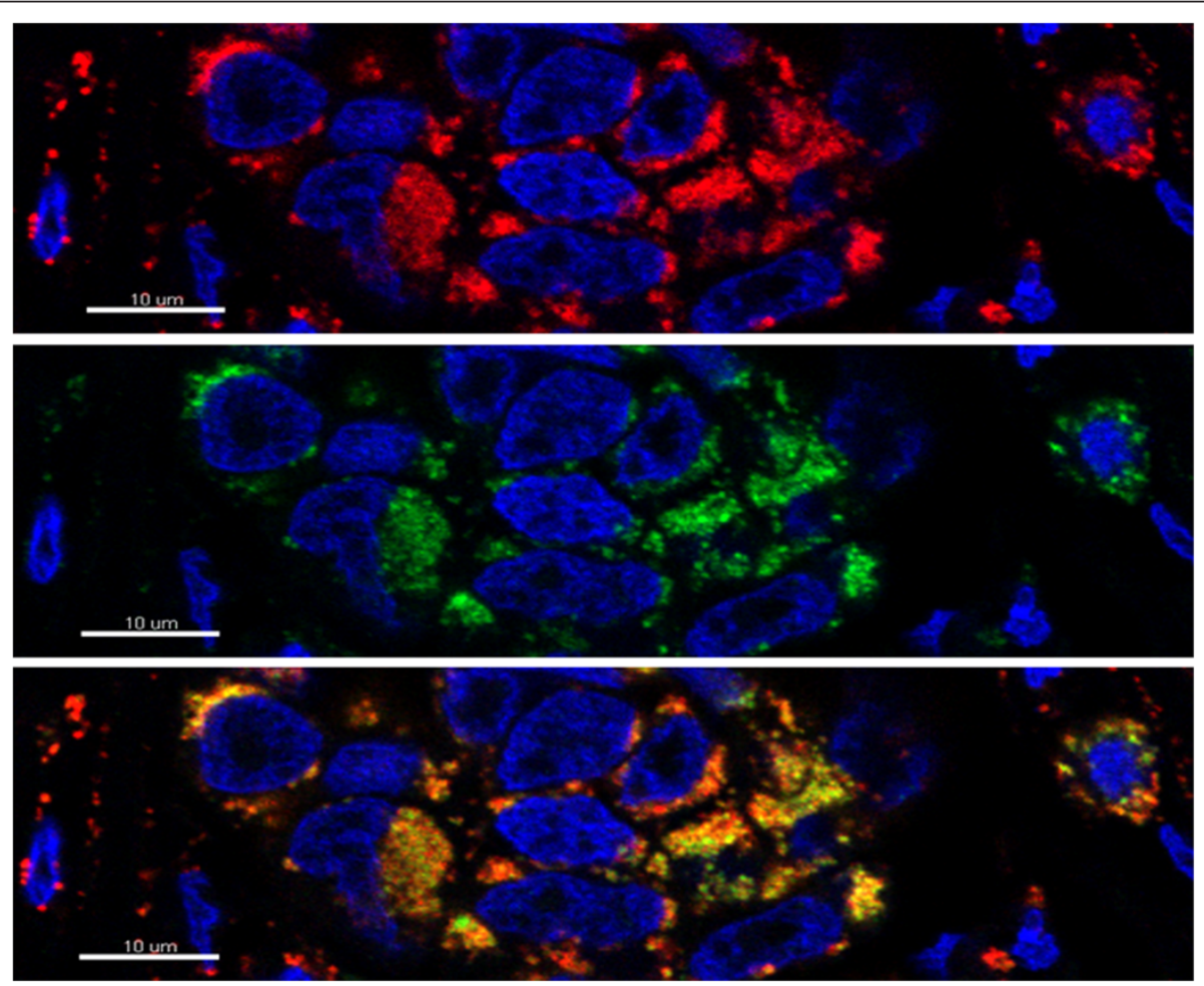

Figure 1 Colocalization analysis of TRAP1 (green) and the mitochondrial marker COX5 (red) using double-immunofluorescence staining in an EOC sample. The images show that both TRAP1 and COX5 are localized in the mitochondria. (Pictures were taken with the confocal microscope LSM700). 

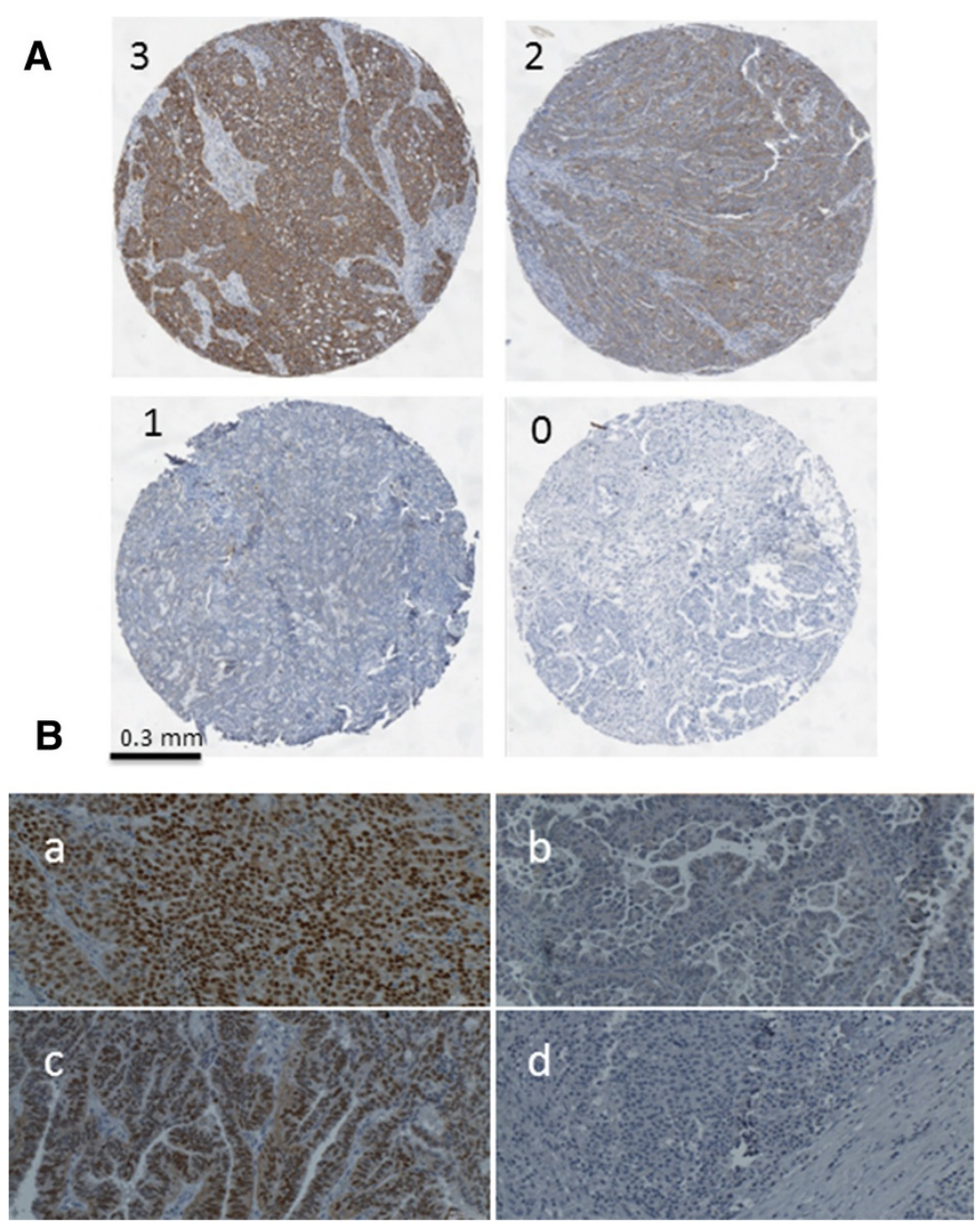

Figure 2 A) Representative immunohistochemical staining of TRAP1 in four different EOC samples classified as TRAP1 negative (0); weak (1); moderate (2); and strong (3); surrounding stromal tissue showed no TRAP1 staining; B) Staining of ERa (a, c) highly positive (strong intensity of nuclear staining, $>80 \%$ positive nuclei), (b) $<10 \%$ of nuclei show weak staining, and (d) completely negative for nuclear ERa staining, were scored as ERa negative. Pictures were taken using TissueFAXS (TissueGnostics; Vienna, Austria).

histology were more likely to be ER $\alpha$ negative (adj. $\mathrm{p}=0.045)$.

To determine the relationship between ER $\alpha$ expression and TRAP1 expression, the Chi-square test was used. Ovarian cancer tissues expressing ER $\alpha$ were more likely to show high TRAP1 expression levels $(67.0 \%, \mathrm{p}<0.001)$. Correspondingly, low TRAP1 expression levels were found in the majority of ER $\alpha$ negative tissues. Still, $42.2 \%$ of ER $\alpha$ negative samples presented high TRAP1 levels.

\section{Relevance of ERa and TRAP1 expression for chemotherapy response and patients' survival}

In Table 3A,B the impact of TRAP1, ER $\alpha$, and the combined TRAP1/ER $\alpha$ expression pattern on OS and PFS, together with various clinicopathological parameters considered as potential prognostic factors, is presented. Univariate analyses identified age (in decades) ( $\mathrm{HR}=$ 1.44; 95\%CI [1.21-1.71]), FIGO stage (HR 1.96; 95\%CI
[1.25-3.06]), grade (HR 1.74; 95\%CI [1.05-2.88]), residual tumor load $(\mathrm{HR}=2.35$; 95\%CI [1.54-3.61]), peritoneal carcinomatosis $(\mathrm{HR}=3.01 ; 95 \% \mathrm{CI} \quad[1.75-5.16]), \quad \mathrm{ER} \alpha$ $(\mathrm{HR}=0.56 ; 95 \% \mathrm{CI}[0.37-0.84])$, TRAP1 (HR 0.63; 95\%CI [0.42-0.94]), and the combination pattern ER $\alpha / T R A P 1$ $(\mathrm{HR}=0.49$; $95 \% \mathrm{CI}[0.32-0.75])$ to be significantly associated with OS. For PFS, the parameters age, FIGO-stage, grade, residual tumor load, and peritoneal carcinomatosis showed significant impact (Table 3B).

In a next step, multivariate Cox proportional-hazards regression analyses of patients' OS and PFS, based on clinicopathological factors together with either i) TRAP1 expression, ii) ER $\alpha$ expression or iii) the combination pattern, was performed. Multivariate analyses identified $\mathrm{ER} \alpha$ and TRAP1 to have an independent impact on OS $(\mathrm{HR}=0.51 ; 95 \% \mathrm{CI}$ [0.34-0.77] and $\mathrm{HR}=0.65 ; 95 \% \mathrm{CI}$ [0.43-0.99]), respectively). The TRAP1/ER $\alpha$-combination pattern was an even stronger significant independent 
Table 2 Study population divided into ERa negative (ERa') and ERa positive $\left(\mathrm{ERa}^{+}\right)$

\begin{tabular}{|c|c|c|c|c|}
\hline $\mathrm{N}=\mathbf{2 0 8}$ & $\mathrm{ERa}^{-}$ & $\mathrm{ERa}^{+}$ & & \\
\hline Characteristics & $\overline{n=99(\%)}$ & $\overline{n=109(\%)}$ & $\mathrm{p}$ & Adjusted $\mathrm{p}$ \\
\hline \multicolumn{5}{|l|}{ Age } \\
\hline$\leq 55(n=98)$ & $55(26.4)$ & $43(20.7)$ & & \\
\hline$>55(n=110)$ & $44(21.2)$ & $66(31.7)$ & 0.026 & 0.080 \\
\hline \multicolumn{5}{|l|}{ Histology } \\
\hline Serous $(n=183)$ & $81(38.9)$ & $102(49.0)$ & & \\
\hline Non-serous ${ }^{1}(n=25)$ & $18(8.7)$ & $7(3.4)$ & 0.009 & 0.045 \\
\hline \multicolumn{5}{|l|}{$\mathrm{FIGO}^{2}$} \\
\hline$\|(n=9)$ & $3(1.4)$ & $6(2.9)$ & & \\
\hline III $(n=164)$ & $76(33.6)$ & $88(42.3)$ & $0.158^{2}$ & \\
\hline IV $(n=35)$ & $20(9.6)$ & $15(7.2)$ & & \\
\hline \multicolumn{5}{|l|}{ Grade (1 missing) } \\
\hline Grade $1 \& 2(n=55)$ & $18(8.7)$ & 37 (17.9) & & \\
\hline Grade $3(n=152)$ & $81(39.1)$ & $71(34.3)$ & 0.009 & 0.054 \\
\hline \multicolumn{5}{|l|}{ Residual tumor } \\
\hline no $(n=146)$ & $66(31.7)$ & $80(38.5)$ & & \\
\hline$>0 \mathrm{~cm}(\mathrm{n}=62)$ & $33(15.9)$ & $29(13.9)$ & 0.289 & \\
\hline \multicolumn{5}{|c|}{ Peritoneal Carcinomatosis } \\
\hline no $(n=64)$ & $31(14.9)$ & $33(15.9)$ & & \\
\hline yes $(n=144)$ & $68(32.7)$ & $76(36.5)$ & 0.871 & \\
\hline
\end{tabular}

${ }^{1}$ Endometrioid $(n=9)$, mixed epithelial $(n=9)$, mucinous $(n=1)$, undifferentiated $(n=4)$, and clear-cell carcinoma $(n=2) .{ }^{2}$ Fisher's Exact test.

prognostic factors for OS (HR $=0.41 ; 95 \% \mathrm{CI}[0.27-0.64])$ (Table 3A). Age and peritoneal carcinomatosis showed a comparably strong influence on OS. FIGO stage, residual tumor load and peritoneal carcinomatosis had a significant impact on PFS.

In Table $3 \mathrm{C}$ the impact of TRAP1, ER $\alpha$, and the combined TRAP1/ER $\alpha$ expression pattern on the response to first-line chemotherapy is shown. The risk to be a non-responder was significantly lower in patients with high TRAP1 expression compared to patients with low TRAP1 expression, both, in a univariate $(\mathrm{HR}=0.53 ; 95 \%$ CI $[0.28-1.00])$ and a multivariate analysis $(H R=0.48$; 95\%CI [0.24-0.96]). A similar but not significant impact was found for $E R \alpha$ positivity in a univariate $(H R=0.62$; 95\%CI [0.33-1.17]) and a multivariate analysis ( $\mathrm{HR}=$ 0.53; 95\%CI [0.26-1.05]). Combining both factors, halves the observed risk to be a non-responder compared to the risk of patients with TRAP1 high or ER $\alpha$ positive tumors, in the univariate $(\mathrm{HR}=0.38$; 95\% CI [0.19-0.75]) and multivariate $(\mathrm{HR}=0.24 ; 95 \% \mathrm{CI}[0.11-0.54])$ analysis, indicating an additive effect of both markers.

Figure 3 shows the univariate impact of ER $\alpha$, TRAP1, and the combination pattern on PFS and OS as estimated by Kaplan Meier plots. Stratifying the patients into two groups according to their combined TRAP1/
ER $\alpha$ expression level yields the strongest predictive factor, which was also seen from the corresponding multiple Cox proportional-hazards regression models (data not shown). Patients presenting with a double negative expression pattern (TRAP1-low/ER $\alpha$-) at time of cytoreductive surgery appear to have a considerably decreased OS $(\mathrm{p}<0.001)$ and PFS $(\mathrm{p}=0.005)$ compared to patients with positive expression levels of both or one of the examined parameters (Figure 3). Further stratification of group 2 into TRAP1high/ER $\alpha$ - (group 2a) and TRAP1low/ER $\alpha+$ (group $2 \mathrm{~b}$ ), and TRAP1high/ER $\alpha$ (group 2c) did not improve this predictive capacity, as shown for OS in Figure 4 (differences not significant).

\section{Discussion}

We have evaluated the expression of ER $\alpha$ in EOC together with the expression of TRAP1, that has been described to be up-regulated in vitro in ER positive ovarian cancer cells exposed to estrogen [9]. To our knowledge, this is the first study evaluating the impact of TRAP1 expression on patients' outcome in a large prospectively collected cohort of more than 200 patients with EOC and the first study evaluating the combined prognostic impact of TRAP1 and ER $\alpha$.

Correlation of ER $\alpha$ with TRAP1 was significant, whereby ER $\alpha$ positive tumors presented significantly higher expression levels of TRAP1. However, high TRAP1 levels were also found in $42 \%$ of ER negative tumors, revealing two independent but interconnected parameters i) ER $\alpha$, described to play a dominant role in ovarian cancer [24,25] and ii) TRAP1, a mitochondrial chaperone, selectively up-regulated in tumor cells [19] and up-regulated by estrogen [10].

$E R \alpha$ expression was not significantly associated with stage and grade, which is in accordance with the study of Hecht et al. [26]. Additionally, we found no significant correlation with age, peritoneal carcinomatosis, and residual tumor load. Tumors with non-serous histology were more likely to be $E R \alpha$ negative (adj. $\mathrm{p}=0.045$ ) compared to serous histology, which is in accordance with the findings of Lee et al. [15]. Studies on ER $\alpha$ expression and survival are inconsistent $[12-16,18,27]$. The results of this study show a significantly longer OS for ER $\alpha$ positive patients in a multiple Cox regression analysis. TRAP1 expression showed a significant and independent impact on chemotherapy responder status and on patients' OS. Combining TRAP1 and ER $\alpha$ expression, patients with ER $\alpha$ negative and TRAP1-low expressing tumors, compared to all other combinations, showed a 2.44-fold higher risk to die. This indicates a subcohort of EOC patients presenting with a low TRAP1 expression and a negative estrogen receptor status exhibiting a worse prognosis. 
Table 3 Multiple Cox and logistic regression analyses for (A) overall survival, (B) progression free survival, and (C) chemotherapy response of clinicopathological parameters, ERa, TRAP1, and the ERa/TRAP1 expression pattern

\begin{tabular}{|c|c|c|c|c|c|c|c|c|}
\hline \multicolumn{9}{|l|}{ A) Overall survival } \\
\hline \multirow[t]{2}{*}{$N=208$} & \multirow{2}{*}{\multicolumn{2}{|c|}{ Univariate }} & \multicolumn{6}{|c|}{ Multivariate } \\
\hline & & & \multicolumn{2}{|l|}{ ERa } & \multicolumn{2}{|l|}{ TRAP1 } & \multicolumn{2}{|c|}{ Combination } \\
\hline Characteristics & HR (Cl95\%) & $\mathbf{p}$ & HR (Cl95\%) & $\mathrm{p}$ & HR (CI95\%) & $\mathrm{p}$ & HR (Cl 95\%) & p \\
\hline Age (per decade) & $1.44(1.21-1.71)$ & $<0.001$ & $1.40(1.17-1.68)$ & $<0.001$ & $1.42(1.18-1.71)$ & $<0.001$ & $1.50(1.24-1.82)$ & $<0.001$ \\
\hline Histology (non-serous vs serous) & $1.05(0.57-1.92)$ & 0.874 & $1.20(0.64-2.27)$ & 0.555 & $1.220 .65-2.29)$ & 0.545 & $1.33(0.70-2.52)$ & 0.381 \\
\hline FIGO (IV vs III vs II) & $1.96(1.25-3.06)$ & 0.003 & $1.39(0.85-2.25)$ & 0.187 & $1.38(0.85-2.24)$ & 0.188 & $1.39(0.86-2.27)$ & 0.176 \\
\hline Grade (3 vs 1,2) & $1.74(1.05-2.88)$ & 0.032 & $0.98(0.58-1.67)$ & 0.951 & $1.34(0.67-1.92)$ & 0.631 & $0.96(0.57-1.64)$ & 0.893 \\
\hline Residual tumor (yes vs no) & $2.35(1.54-3.61)$ & $<0.001$ & $1.87(1.21-2.89)$ & 0.005 & $1.79(1.16-2.77)$ & 0.009 & $1.80(1.17-2.78)$ & 0.008 \\
\hline Peritoneal Carcinomatosis (yes vs no) & $3.01(1.75-5.16)$ & $<0.001$ & $2.75(1.56-4.84)$ & $<0.001$ & $2.45(1.38-4.32)$ & 0.002 & $2.68(1.51-4.74)$ & 0.001 \\
\hline $\operatorname{ERa}(1 / 2 / 3$ vs 0$)$ & $0.56(0.37-0.84)$ & 0.005 & $0.51(0.34-0.77)$ & 0.002 & & & & \\
\hline TRAP1 (3 vs $0 / 1 / 2$ ) & $0.63(0.42-0.94)$ & 0.025 & & & $0.65(0.43-0.99)$ & 0.044 & & \\
\hline Combination ERa/TRAP1* & $0.49(0.32-0.75)$ & 0.001 & & & & & $0.41(0.27-0.64)$ & $<0.001$ \\
\hline
\end{tabular}

B) Progression free survival

\begin{tabular}{|c|c|c|c|c|c|c|c|c|}
\hline Characteristics & HR (Cl95\%) & $\mathbf{p}$ & HR (Cl95\%) & $p$ & HR (Cl95\%) & $\mathrm{p}$ & HR (Cl 95\%) & $\mathrm{p}$ \\
\hline Age (per decade) & $1.21(1.06-1.38)$ & 0.041 & $1.14(0.99-1.31)$ & 0.056 & $1.15(1.00-1.32)$ & 0.055 & $1.17(1.02-1.35)$ & 0.027 \\
\hline Histology (non-serous vs serous) & $0.91(0.55-1.49)$ & 0.701 & $1.23(0.72-2.11)$ & 0.453 & $1.25(0.73-2.15)$ & 0.416 & $1.25(0.72-2.14)$ & 0.428 \\
\hline FIGO (IV vs III vs II) & $2.48(1.69-3.62)$ & $<0.001$ & $1.85(1.22-2.79)$ & 0.004 & $1.91(1.26-2.89)$ & 0.002 & $1.91(1.26-2.89)$ & 0.002 \\
\hline Grade (3 vs 1,2) & $1.49(1.03-2.17)$ & 0.035 & $0.93(0.62-1.39)$ & 0.721 & $0.95(0.64-1.41)$ & 0.794 & $0.89(0.59-1.33)$ & 0.559 \\
\hline Residual tumor yes vs no) & $1.99(1.45-2.75)$ & $<0.001$ & $1.56(1.11-2.18)$ & 0.010 & $1.55(1.10-2.17)$ & 0.011 & $1.56(1.11-2.18)$ & 0.010 \\
\hline Peritoneal Carcinomatosis (yes vs no) & $2.96(2.01-4.37)$ & $<0.001$ & $2.98(1.95-4.55)$ & $<0.001$ & $2.92(1.91-4.47)$ & $<0.001$ & $3.00(1.96-4.60)$ & $<0.001$ \\
\hline $\operatorname{ERa}(1 / 2 / 3$ vs 0$)$ & $0.84(0.62-1.15)$ & 0.279 & $0.80(0.58-1.11)$ & 0.185 & & & & \\
\hline TRAP1 (3 vs 0/1/2) & $0.87(0.63-1.18)$ & 0.367 & & & $0.87(0.63-1.20)$ & 0.398 & & \\
\hline Combination ERa/TRAP1* & $0.79(0.56-1.12)$ & 0.188 & & & & & $0.70(0.48-1.02)$ & 0.061 \\
\hline \multicolumn{9}{|l|}{ C) Chemotherapy response } \\
\hline Characteristics & HR (Cl95\%) & $\mathrm{p}$ & HR (Cl95\%) & $\mathrm{p}$ & HR (Cl95\%) & $\mathrm{p}$ & HR (Cl 95\%) & $\mathrm{p}$ \\
\hline Age (per decade) & $1.33(1.02-1.74)$ & 0.036 & $1.42(1.06-1.9)$ & 0.019 & $1.43(1.06-1.91)$ & 0.019 & $1.57(1.15-2.15)$ & 0.005 \\
\hline Histology (non-serous vs serous) & $0.74(0.26-2.08)$ & 0.567 & $0.92(0.30-2.83)$ & 0.889 & $0.93(0.30-2.83)$ & 0.893 & $0.88(0.28-2.73)$ & 0.824 \\
\hline FIGO (IV vs III vs II) & $2.06(1.02-4.15)$ & 0.044 & $1.59(0.73-3.49)$ & 0.241 & $1.65(0.76-3.61)$ & 0.207 & $1.67(0.75-3.72)$ & 0.205 \\
\hline Grade (3 vs 1,2) & $1.17(0.56-2.44)$ & 0.683 & $0.72(0.32-1.64)$ & 0.437 & $0.76(0.33-1.72)$ & 0.505 & $0.56(0.23-1.33)$ & 0.188 \\
\hline Residual tumor (yes vs no) & $1.96(1.01-3.80)$ & 0.046 & $1.35(0.67-2.75)$ & 0.411 & $1.43(0.71-2.91)$ & 0.318 & $1.36(0.66-2.81)$ & 0.408 \\
\hline Peritoneal Carcinomatosis (yes vs no) & $3.01(1.32-6.85)$ & 0.009 & $3.04(1.25-7.36)$ & 0.014 & $2.89(1.19-7.01)$ & 0.018 & $3.34(1.34-8.36)$ & 0.009 \\
\hline $\operatorname{ERa}(1 / 2 / 3$ vs 0$)$ & $0.62(0.33-1.17)$ & 0.138 & $0.53(0.26-1.06)$ & 0.071 & & & & \\
\hline TRAP1 (3 vs 0/1/2) & $0.53(0.28-1.00)$ & 0.050 & & & $0.48(0.24-0.96)$ & 0.037 & & \\
\hline Combination ERa/TRAP1* & $0.38(0.19-0.75)$ & 0.005 & & & & & $0.24(0.11-0.54)$ & $<0.001$ \\
\hline
\end{tabular}

*ERa and/or TRAP1 high vs ERa- and TRAP1 low.

Up to now, only one study has addressed TRAP1 protein expression in human ovarian cancer tissue in regard to therapy response. Walker et al. have described significantly increased expression levels of TRAP1 in Letrozole-sensitive tumors if compared to resistant tumors, suggesting that endocrine responsiveness might be predictable with the help of estrogen regulated genes and their expression levels [10]. Still, the association of TRAP1 expression in patients receiving Letrozole therapy and response has not been investigated in a multivariate model, and thus, the independent impact of TRAP1 on response to therapy remains unclear. Therefore, we focused on the predictive independent impact of TRAP1 and ER $\alpha$ on response to standardized chemotherapy and on patients' outcome. In accordance with the study of Walker et al. [10], our results show that high TRAP1 expression is positively associated with therapy-response. Patients with high TRAP1 expression have a two-fold higher response-rate to first-line chemotherapy. Similarly, patients with ER $\alpha$ positive tumors 

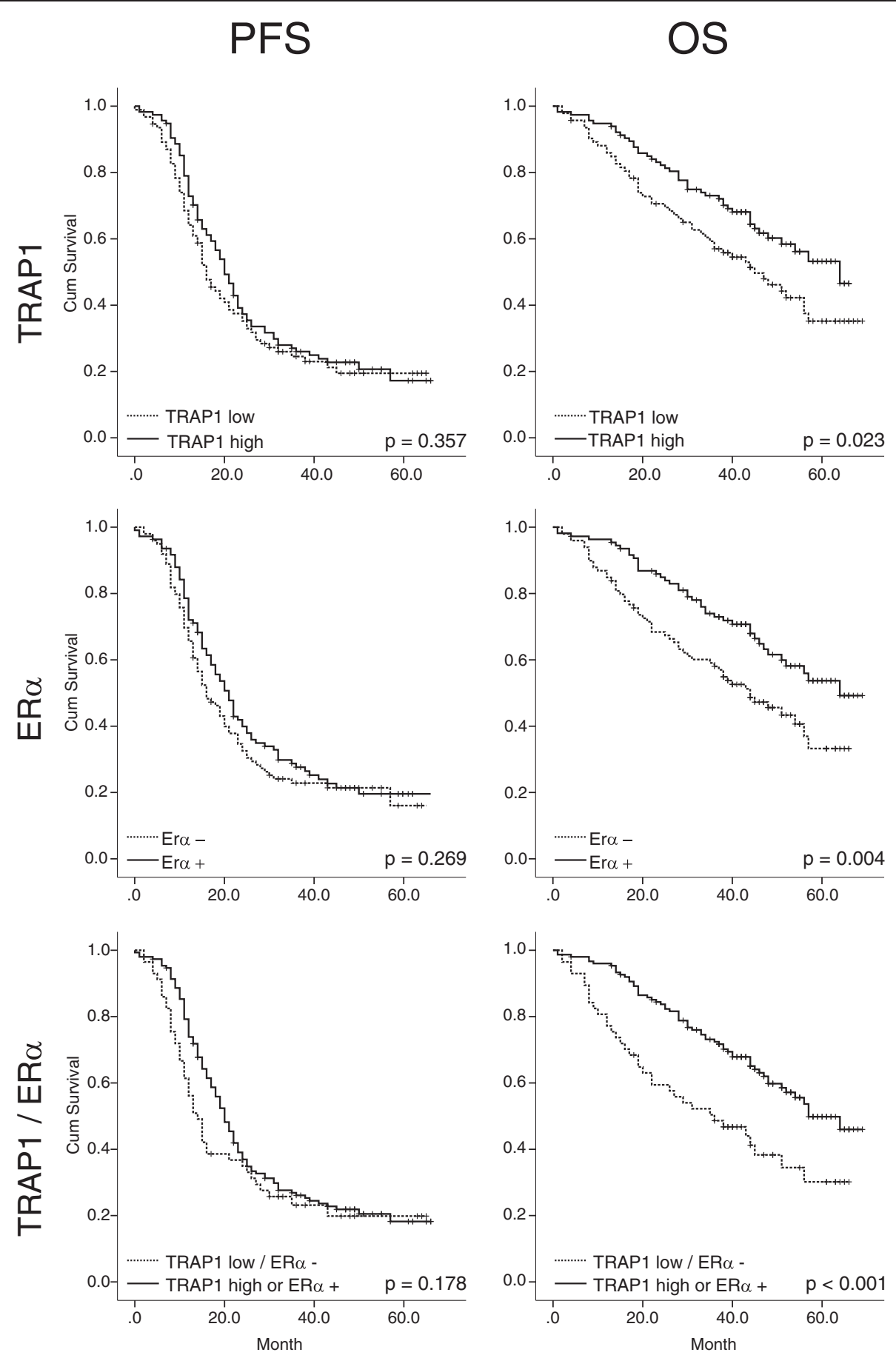

Figure 3 Kaplan-Meier estimates of the impact of TRAP1, ERa, and the combination pattern on PFS and OS ( $p$ values determined by the log-rank test).

show a two-fold higher response rate, but only as trend when corrected for clinicopathological parameters. For the combined expression pattern of TRAP1 and ER $\alpha$, a more than four-fold higher risk to be a chemotherapy non-responder for patients with TRAP1 weak and ER $\alpha$ negative tissues could be observed $(\mathrm{p}<0.001)$. Most of the current knowledge on TRAP1 has been derived by cell-line models and mouse-models [28,29]. This is the first study investigating TRAP1 in the complex biology of EOC patients treated with standardized chemotherapy. In cell line models investigating Cisplatin resistance only weak differences in the TRAP1 expression (1.1-1.2 


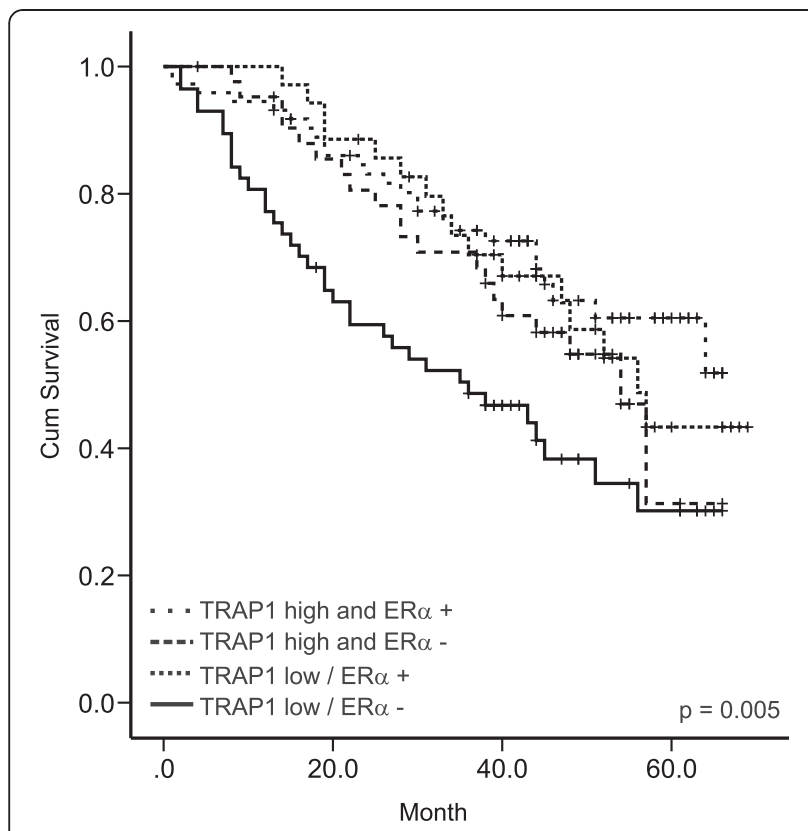

Figure 4 Kaplan-Meier estimates comparing the impact of all four groups of the combined TRAP1-ERa pattern on OS. Black line: ERa negative/TRAP1-low; dotted black line: ERa negative/ TRAP1-high; grey line: ERa positive/TRAP1-high; dotted grey line: ERa positive/TRAP1-low.

fold) between resistant and sensitive cells were observed [8]. The authors therefore concluded that TRAP1 might not lead to resistance in an in vitro model.

As shown with small interfering RNA gene-silencing of TRAP1 in a lung cancer cell line and re-expression in a breast cancer cell line, TRAP1 expression seems not to be associated with apoptosis [30]. This is in conflict with a variety of studies, proposing anti-apoptotic and anti-oxidative functions of TRAP1 [19,20,29]. As shown above for human EOC patients, high TRAP1 expression - as determined by immunohistochemistry reveals significantly better response to chemotherapy and a longer OS. To better understand the conflicting data within different in vitro models and between some in vitro models and our in vivo survival analyses, the role of TRAP1 in EOC needs to be further elucidated.

\section{Conclusion}

As only few studies are available on the role of TRAP1 in EOC, this study enhances the knowledge upon the crosstalk between TRAP1 and ER $\alpha$ in clinical samples. However, caution is needed in the biological interpretation of TRAP1's role in human EOC. Indeed, several reports suggested that TRAP1 is involved in protection from apoptosis. Thus, the finding that EOC patients with high TRAP1 expression are characterized by an advantage in chemotherapy response and overall survival would suggest a converse involvement of TRAP1 in an in vivo setting, e. g. that TRAP1 is a (surrogate) marker for stressed, thus apoptosis prone, tumor cells. This would explain the positive impact of high TRAP1 expression on chemotherapy response and overall survival. In such a perspective, further studies in either EOC cell lines or human EOC series are needed to understand the biological and clinical role of HSP90 chaperones in ovarian carcinogenesis.

\section{Additional file}

\section{Additional file 1: Supplementary data.}

\section{Conflicts of interests}

The authors have no conflicts of interest to declare.

\section{Acknowledgements}

This work was supported by the Sixth Framework Programme (FP6) Project of the European Union (EU) called "Ovarian Cancer: Diagnosis of a silent killer - OVCAD", no. 018698 and "Nationalbank"-project no. 14595.

\section{Author details}

${ }^{1}$ Department of Obstetrics and Gynecology Molecular Oncology Group, Medical University of Vienna, Vienna, Austria. ${ }^{2}$ Department of Gynecology Campus Virchow Klinikum, Charite Medical University, Berlin, Germany.

${ }^{3}$ Department of Gynecology and Gynecologic Oncology, University Medical Center Hamburg-Eppendorf, Hamburg, Germany. ${ }^{4}$ Department of Obstetrics and Gynecology, University Hospitals Leuven, Katholieke Universiteit Leuven, Leuven, Belgium. ${ }^{5}$ Division of Gynaecological Oncology, Department of Obstetrics and Gynaecology, MUMC+ GROW School for Oncology and Developmental Biology, PO Box 5800, Maastricht 6202AZ, The Netherlands. ${ }^{6}$ Clinical Institute of Pathology, Medical University of Vienna, Vienna, Austria.

Received: 18 May 2012 Accepted: 4 September 2012

Published: 14 September 2012

\section{References}

1. Leav I, Plescia J, Goel HL, Li J, Jiang Z, Cohen RJ, Languino LR, Altieri DC: Cytoprotective mitochondrial chaperone TRAP-1 as a novel molecular target in localized and metastatic prostate cancer. Am J Pathol 2010, 176:393-401.

2. Costantino E, Maddalena F, Calise S, Piscazzi A, Tirino V, Fersini A, Ambrosi A, Neri V, Esposito F, Landriscina M: TRAP1, a novel mitochondrial chaperone responsible for multi-drug resistance and protection from apoptotis in human colorectal carcinoma cells. Cancer Lett 2009, 279:39-46.

3. Calderwood SK: Heat shock proteins in breast cancer progression-a suitable case for treatment? Int J Hyperthermia 2010, 26:681-685.

4. Landriscina M, Amoroso MR, Piscazzi A, Esposito F: Heat shock proteins, cell survival and drug resistance: the mitochondrial chaperone TRAP1, a potential novel target for ovarian cancer therapy. Gynecol Oncol 2010, 117:177-182.

5. Cohen $M$, Dromard $M$, Petignat $P$ : Heat shock proteins in ovarian cancer: a potential target for therapy. Gynecol Oncol 2010, 119:164-166.

6. Langmar Z, Vlesko G: The potential role of heat shock proteins in the treatment of ovarian cancer. Orv Hetil 2011, 152:92-95.

7. Fraser M, Leung B, Jahani-Asl A, Yan X, Thompson WE, Tsang BK: Chemoresistance in human ovarian cancer: the role of apoptotic regulators. Reprod Biol Endocrinol 2003, 1:66.

8. Yamamoto K, Okamoto A, Isonishi S, Ochiai K, Ohtake Y: Heat shock protein 27 was up-regulated in cisplatin resistant human ovarian tumor cell line and associated with the cisplatin resistance. Cancer Lett 2001, 168:173-181.

9. O'Donnell AJ, Macleod KG, Burns DJ, Smyth JF, Langdon SP: Estrogen receptor-alpha mediates gene expression changes and growth response in ovarian cancer cells exposed to estrogen. Endocr Relat Cancer 2005, 12:851-866 
10. Walker G, MacLeod K, Williams AR, Cameron DA, Smyth JF, Langdon SP: Estrogen-regulated gene expression predicts response to endocrine therapy in patients with ovarian cancer. Gynecol Oncol 2007, 106:461-468.

11. Schlumbrecht MP, Xie SS, Shipley GL, Urbauer DL, Broaddus RR: Molecular clustering based on ERalpha and EIG121 predicts survival in high-grade serous carcinoma of the ovary/peritoneum. Mod Pathol 2011, 24:453-462.

12. Halon A, Materna V, Drag-Zalesinska M, Nowak-Markwitz E, Gansukh T, Donizy P, Spaczynski M, Zabel M, Dietel M, Lage H, Surowiak P: Estrogen receptor alpha expression in ovarian cancer predicts longer overall survival. Pathol Oncol Res 2011, 17:511-518.

13. Burges A, Bruning A, Dannenmann C, Blankenstein T, Jeschke U, Shabani N, Friese K, Mylonas I: Prognostic significance of estrogen receptor alpha and beta expression in human serous carcinomas of the ovary. Arch Gynecol Obstet 2010, 281:511-517.

14. Hogdall EV, Christensen L, Hogdall CK, Blaakaer J, Gayther S, Jacobs IJ, Christensen IJ, Kjaer SK: Prognostic value of estrogen receptor and progesterone receptor tumor expression in Danish ovarian cancer patients: from the 'MALOVA' ovarian cancer study. Oncol Rep 2007, 18:1051-1059.

15. Lee P, Rosen DG, Zhu C, Silva EG, Liu J: Expression of progesterone receptor is a favorable prognostic marker in ovarian cancer. Gynecol Oncol 2005, 96:671-677.

16. Tangjitgamol S, Manusirivithaya S, Khunnarong J, Jesadapatarakul S, Tanwanich S: Expressions of estrogen and progesterone receptors in epithelial ovarian cancer: a clinicopathologic study. Int J Gynecol Cancer 2009, 19:620-627.

17. Yang $X Y$, Xi MR, Yang KX, Yu H: Prognostic value of estrogen receptor and progesterone receptor status in young Chinese ovarian carcinoma patients. Gynecol Oncol 2009, 113:99-104.

18. Munstedt K, Steen J, Knauf AG, Buch T, von Georgi R, Franke FE: Steroid hormone receptors and long term survival in invasive ovarian cancer. Cancer 2000, 89:1783-1791.

19. Kang BH, Plescia J, Dohi T, Rosa J, Doxsey SJ, Altieri DC: Regulation of tumor cell mitochondrial homeostasis by an organelle-specific Hsp90 chaperone network. Cell 2007, 131:257-270.

20. Montesano Gesualdi N, Chirico G, Pirozzi G, Costantino E, Landriscina M, Esposito F: Tumor necrosis factor-associated protein 1 (TRAP-1) protects cells from oxidative stress and apoptosis. Stress 2007, 10:342-350.

21. Spentzos D, Levine DA, Kolia S, Otu H, Boyd J, Libermann TA, Cannistra SA: Unique gene expression profile based on pathologic response in epithelial ovarian cancer. J Clin Oncol 2005, 23:7911-7918.

22. Iba T, Kigawa J, Kanamori Y, Itamochi H, Oishi T, Simada M, Uegaki K, Naniwa J, Terakawa N: Expression of the c-myc gene as a predictor of chemotherapy response and a prognostic factor in patients with ovarian cancer. Cancer Sci 2004, 95:418-423.

23. Bretz F, Maurer W, Brannath W, Posch M: A graphical approach to sequentially rejective multiple test procedures. Stat Med 2009, 28:586-604.

24. Ho SM: Estrogen, progesterone and epithelial ovarian cancer. Reprod Biol Endocrinol 2003, 1:73.

25. Arias-Pulido H, Smith HO, Joste NE, Bocklage T, Qualls CR, Chavez A, Prossnitz ER, Verschraegen CF: Estrogen and progesterone receptor status and outcome in epithelial ovarian cancers and low malignant potential tumors. Gynecol Oncol 2009, 114:480-485.

26. Hecht JL, Kotsopoulos J, Hankinson SE, Tworoger SS: Relationship between epidemiologic risk factors and hormone receptor expression in ovarian cancer: results from the Nurses' Health Study. Cancer Epidemiol Biomarkers Prev 2009, 18:1624-1630.

27. Liu JF, Hirsch MS, Lee H, Matulonis UA: Prognosis and hormone receptor status in older and younger patients with advanced-stage papillary serous ovarian carcinoma. Gynecol Oncol 2009, 115:401-406.

28. Amoroso MR, Matassa DS, Laudiero G, Egorova AV, Polishchuk RS, Maddalena F, Piscazzi A, Paladino S, Sarnataro D, Garbi C, et al: TRAP1 and the proteasome regulatory particle TBP7/Rpt3 interact in the endoplasmic reticulum and control cellular ubiquitination of specific mitochondrial proteins. Cell Death Differ 2011, 19:592-604.

29. Felts SJ, Owen BA, Nguyen P, Trepel J, Donner DB, Toft DO: The hsp90related protein TRAP1 is a mitochondrial protein with distinct functional properties. J Biol Chem 2000, 275:3305-3312.

30. Liu D, Hu J, Agorreta J, Cesario A, Zhang Y, Harris AL, Gatter K, Pezzella F: Tumor necrosis factor receptor-associated protein 1(TRAP1) regulates genes involved in cell cycle and metastases. Cancer Lett 2010, 296:194-205.

doi:10.1186/1476-4598-11-69

Cite this article as: Aust et al:: Role of TRAP1 and estrogen receptor alpha in patients with ovarian cancer -A study of the OVCAD consortium. Molecular Cancer 2012 11:69.

\section{Submit your next manuscript to BioMed Central and take full advantage of:}

- Convenient online submission

- Thorough peer review

- No space constraints or color figure charges

- Immediate publication on acceptance

- Inclusion in PubMed, CAS, Scopus and Google Scholar

- Research which is freely available for redistribution

Submit your manuscript at www.biomedcentral.com/submit
C Biomed Central 